\title{
Envisioning ambiances: Representing (past, present and future) atmospheres for architecture and the built environment
}

\author{
Laurent Lescop ${ }^{1}$, Anetta Kepczynska-Walczak ${ }^{2}$ \\ ${ }^{1}$ ENSA Nantes - CRENAU/AAU UMR-CNRS1563, France \\ ${ }^{2}$ Department of Digital Technologies in Architecture and Urban Planning, Institute of Architecture \\ and Urban Planning, Lodz University of Technology, Lodz (Łódź), Poland
}

\begin{abstract}
The concept of "ambiance" has been shaped over the years by questioning the interactions between three attractors: architecture and the city, climatic and sound phenomena, uses and perception. Studied in pairs, each of these attractors refers to very different disciplinary fields; architecture and phenomena concern the physics of the city, architecture and uses interest sociology and uses and phenomena are rather turned to comfort. Studies concerning ambiances are therefore highly interdisciplinary and raise many questions: living spaces, urban renewal and heritage, urban prospective and the city as a stage. For this, many conceptual and technical tools are mobilized: digital tools for simulation and immersion, investigation, surveys and storytelling, prototyping, field action. What may be new in the field of academic studies is the awareness of artistic creation as a resource for the use of digital tools, storytelling and the representation of complexity through original means.
\end{abstract}

\section{Ambiance as reference}

The term of "ambiance" is a relatively recent one. It appeared for the first time in Les Nouveaux Contes cruels de Villiers by Villiers de l'Isle-Adam, in 1885. In the amour sublime short story, the author invents this word as he plays with sounds, as it was often the case at this time. Therefore, nouns like regrettance, reluctance, vibrance, tremblance were created. In the original text, the quotation appears as follows: "Évariste, - nous l'avons donné à entendre, - était un de ces hommes qui s'expliquent les choses sans jamais s'emporter, son calme énergique lui conférant le don d'étiqueter toujours, d'une manière sérielle, un fait quelconque, sans l'isoler de son ambiance, - et, par conséquent, de le dominer, en l'utilisant même, s'il se pouvait, - dans la mesure du convenable, bien entendu." Ambiance, coming from literature, was transferred to common language via the technical vocabulary used in painting to describe something phenomenological, then cinema, to identify a sound or a light, which helps to characterise a place. After the creation of the CERMA laboratory at the beginning of the 1970s, then in collaboration with the CRESSON laboratory within a dedicated UMR, the term of "ambiance", sometimes used in the plural, was used to describe the complex relationships between a place designated by its architecture, atmospheric and 
sound phenomena and the users' perception. By associating many competences for the description and simulation of the physics of phenomena and the understanding of urban practices, research works on ambiances aim to associate quantitative and qualitative dimensions in order to improve the design process of the architectural project.

The substantive "ambiance" does not have a direct translation in foreign languages, and the outlines of its definition remain blurry. The first English occurrence of the term came shortly after Villiers de l'Isle-Adam's invention. Theodore Child used the term in an article for Harper's called "American Artists at the Paris Exhibition". He stated, "Thus, before we realize what the picture is, we already receive an impression of something rich, rare, and precious, and at the same time of something exquisite and quintessential, for the form which we discern in the dreamy ambience is of supreme elegance and fearless purity of line" ( $\mathrm{p}$. 500). The spelling of ambience should be noted, while the ambiance version also existed, but was more seldom used. Indeed, in many languages, ambiance is often translated as atmosphere. Therefore, ambiance can be found as atmosphäre and ambiente in German. Ambiente is also the Italian translation, with a broader meaning. If the concept is studied phenomenologically, the term stimmung is more often used to refer to ambiances as sensitive particularities of a space. Stimmung is a musical term, with the same root as stimme, the voice, and it means tuning, tonality or effect. It also refers to a mood. In music, the emergence of what I would call a secret emotion, as its origin and explanation are not easy to pinpoint, takes place through a work of skilful variation around repetitive themes or the sound of the same tune. Such is the case of Stockhausen, who, by playing with duration, throws his audience into a hypnotising and meditative universe.

\section{Ambiance as method}

The contributions to the fourteenth EAEA conference prove that, beyond its actual definition, ambiance brings the research community together around questions regarding intangibility, perception mechanisms, and more broadly around the search for a non-demonstrative form of quality. It is thus a keyword, which we use as much to open a phenomenological approach of ecosystems, whether natural or built where humans interact, as to describe in a more specific way a prominent phenomenon, i.e. the sound, aeraulic or thermal ambiance of a place. It is also, and perhaps more importantly, a grammatical word that is required to understand and design places. Indeed, it entails taking into account the physical and symbolic interactions of atmospheric, sound, use phenomena in the built space, within the analysis and the conception.

If we consider the year 1995 as our starting point to locate the first definitions of ambiances, it appears that the concept has become richer, twenty years later, and has spread across the world, in turn making it harder to understand. Jean-Paul Thibaud wrote that "the ambiance escapes", which implies both the enrichment of the concept and the complexity to fully grasp it. The ultimate risk and the crisis to come would be to state that everything is ambiance, therefore preventing any attempts at delineating a proper subject. For now, let us go back to one of the most frequent uses: the perspective of ambiance.

The notion of architectural design presupposes that a representation phase will be needed. According to the canonical diagram, the design process goes is accompanied by sketches, which gradually transform as the project is defined, from a cursive and personal expression to a standardised layout. Within this process, the ambiance drawing accounts for qualitative 
aspects by assuming a perspective that is close to the future user's point of view. Therefore, there lies the first conceptual stake: the representation of ambiances, i.e. the graphical transcription of the perception of space and, consequently, the representation of intangibility. The creation of a corpus of graphical figurations of climatic and sound phenomena, of transcription of perceptions of places, is an essential step. The contributions hereinafter propose many ideas to enrich our graphical and instrumental universe. The experiences and realisations that are presented in this volume show how we can combine the project with precise indications in terms of intentions for control and regulation of lighting or sound, for example. It allows to go to the next step, which is the interaction between phenomena and perception mechanisms. It would be too hasty to consider that the construction of perception only involves the five senses, with touch dealing with what is the closest to us and sight and hearing with what is the furthest away. Effectively, the information is organised in batches, regardless of distance. We could call the intelligibility "background", and use the term "salience" for the sensitive qualification of an environment, with the appreciation of one or the other of these aspects. The background is a presence in which the information is perceptible and undefined, similar to a landscape from afar, where it would be hard to distinguish the components in detail, but still representing a coherent whole. Another example would be the urban rumour, which we can perceive, although we cannot separate its origin and the nature of the different sounds. The intelligibility is a whole, of which we can pinpoint the components and specify them. Lastly, the salience is a phenomenon that stems from an ensemble, which can sometimes characterise it, similar to a light beam that would mean that a room is sunlit, or an airplane, which would imply a sound nuisance.

Therefore, the conceptual enrichment gives the project not only a shape, but also a phenomenological aspect that belongs to a context.

\section{Ambiance and education}

The contributions that the reader will discover hereafter highlight the fact that education around a project is mainly based on the mastery of means of representation. This projectbased education relies on three pillars: notional, referential and projectual. The notional pillar involves the broad fields of knowledge to identify schools of thought and conceptual tools, in order to embed them into the evolution of ideas. Architecture, intrinsically pluridisciplinary, nurtures itself with different sources, both theoretical and technical. The referential element represents the identification of trajectories within the architectural field, which can be recognised in the history of architectural styles, doctrines, building techniques or ideologies supporting realisations. Lastly, the projectual aspect spans the processes and techniques allowed to produce a built space. Researchers working on ambiances can find themselves in at least two of these notions.

The representation stage adds to the cognitive aspects supporting the perception of a place by connecting it to a context, a temporal dynamic, the identification of sensitive figures, symbolic values, or a certain attention. In the corpus of works on ambiances, and in some articles of this book, it is possible to find propositions to organise some of those registers into partitions to generate a synoptic reading. Beyond the academic world and within scenography and classical painting, many effective solutions exist, which associate sensitive analysis and technical implementation, similar to the architectural project. The result serves the storytelling: the ambiance becomes an actualised, and denotated, space. It is characterised by elements that connect it to a distant, fictional or not, "elsewhere", creating imitation or 
resemblance. We can distinguish three groups of space facilitating denotation. Firstly, the topical, i.e. a configuration associated with a sort of platitude, but whose elements and their articulation are found everywhere, with slight differences. For example, we can mention the village square. Secondly, we can find the archetypical, which refers to extraordinary forms that are easily identified and identical, e.g. restaurants and hotel chains. Lastly, the synecdoche of ambiance represents spaces where only one component is enough to identify all the others. Therefore, an armchair, a lamp and a television are enough to signify an indoor environment. These three groups represent what scenography proposes in terms of décor, and would be recognised in everyday spatial experiments, even highlighted when it comes to the augmented city.

For students, the validation of their hypotheses inevitably involves the project and the implementation of different configurations to perceive the influence and the variability of each factor, while still ensuring a phenomenological approach. Indeed, we should avoid the fragmentation of the analysis, which would produce reversed or biased results. For obvious practical matters, we use virtual technologies and immersion to start understanding how phenomena work and test their intensity on the audience. From then on, a new question arises to characterise the research protocol. From a neuronal point of view, we now know that a virtual experience is lived in similar ways to a real one. However, an in-depth reflection still needs to be carried out, on what we consider as "immersion", and on the nature of the mobilised devices. In other words, we need to work on both the form and the content.

\section{Ambiance and digital instruments}

One of the stakes mentioned in some contributions is the role of digital tools in education, and, thus in the design community. Two main dimensions characterise ongoing studies: immersion and parametric conception. They are both paving the way, which the field of ambiances is only starting to explore. The articles presented at EAEA14 on this theme will notably represent progress in that vein.

Immersive instruments have a very long history already, if we consider the fact that they represent the association of an illusory technical device, an ambiance setting and storytelling. Panoramas, created in the $18^{\text {th }}$ century and made popular in the $19^{\text {th }}$ century, already addressed most characteristics by proposing virtual journeys to a faraway "elsewhere". Ambiances have since long been one of the features of panoramas, trying to control lighting, sound, then atmosphere, sometimes even smells as the image became more real and the staging more spectacular. Similarly, theatre, seeking to abandon the constraining central perspective and frontal organisation, tried with Apia and Gropius to conceive a total show. Over this aesthetic and conceptual research, three movements started appearing, which would characterise immersion until today. The first is the envelopment of the audience as their visual space overflows. The second is the distance from the real world by stupefaction, when it overloads them with new sensory information. The third is the commitment to the virtual world, thanks to interaction interfaces, whether real or not. The combination of these three aspects gives the illusion of stepping into a diegetic space, of walking on the other side of the screen. If sight and hearing are easily mobilised, it is possible to find systems that reproduce airflows, smells, thermal engineering and kinaesthesia. Generally, the devices rely on the users' synaesthesic abilities, leaving them to mentally re-develop the missing sensory information. Designing sensory stimulations often goes with the question of simulating light, sound, smells - and we are thus back to the ambiances. 


\section{Ambiance and physical phenomenology}

Immersion is often described as the alternative to reality. However, it also represents a constitution, as a set of new, unprecedented perceptions that can be experienced freely. The evolution introduced in the contributions shows how to virtually experiment physical phenomena by associating simulation and lived experience. Connecting the phenomenology of perceptions with the physical understanding of thermal, aeraulic, sound and light phenomena develops a global approach that is theorised by research works on cognitive architecture and studies on architecture and neurosciences. By the characterisation of the stories that accompany the sensitive experience, the ambiances highlight the fact that we do not perceive passively, but that we actively select within our Umwelt, even to the point of making us believe that we can modify or act on it. "The privilege of humans is, in a way, to create worlds, to have at least the illusion that they can escape their Umwelt!" wrote Alain Berthoz about simplexity. This implies that it is less about exploring the process of direct perception and more the formulation mechanism of these worlds.

This is the reason why we can be very sensitive to objects, elements or events that put our everyday perception off-centre, which we can see appear in urban scenographical experiences. Digital tools greatly help in the teaching of these aspects and in the design within projects. The latter do not have to be realisations for the contemporary world. They can be mobilised to convey historical ambiances. They can also offer an archaeology of ambiances as to no longer work on the object or the form only, but also on the context, the use and the symbolic representations. These themes, sometimes highly speculative, still renew some questions. They also help to understand what is permanent on a given territory.

\section{Ambiance and heritage}

To commemorate the centenary of the Bauhaus, while wars and accidents lead to the destruction of architectural tradition, questions on the knowledge and preservation of heritage are even more relevant. Studies on Łódź's industrial heritage, military heritage, as well as all sorts of knowledge and vernacular history prove that the consideration of ambiances allows both to enrich hypotheses with restitutions and with fine-tuned knowledge by distancing us from a pure object-based approach.

In Dessau, the answer given by Bruno Fioretti Marquez Architects, based in Berlin, is so provocative that it invites us to rethink the question of heritage in terms of ambiances. Inspired by writers, such as Thomas Demand, Hiroshi Sugimoto and Jorge Luis Borges, architect José Gutierrez Marquez stated during the inauguration of his project that "Our memory lives off blurriness and imprecision". The idea of a blurry memory is formally translated as a very light grey colour, uniform, inside and outside. The windows are transparent. From inside, the landscape appears uncertain and far away. From outside, the interior does not enable introspection. The built volume no longer houses a home; it is an empty shell, barely sculpted by a few lines in relief. This is not architecture anymore, but a geometric outline, where form does not follow function - it represents a sort of mould of the memory of the old building. This reinterpretation is iconoclastic, and it runs away from the picturesque, historical fetishization and subservience to the image. To mention the question from the first chapter, we can ask - what does this construction denotate? Certainly not the Bauhaus, since we cannot find spatial articulations, games of openings or even technical details that preserve buildings from time. It perhaps rather denotes Lyonel Feininger's work 
on colours and László Moholy-Nagy's greys and light. Either way, it sets up an outside environment that does not predict the inside one - the house tells a story that plays on discontinuities. Should we follow that path, should we stay on that of imitation as it is the case nowadays, should we freeze movement to maintain the memory?

\section{Envisioning ambiances}

The undetectable imitation, which would deceive our senses enough to be unable to spot what the misleading artifice, is the fantasy of perfect reproduction of phenomena or objects, of undetectable immersion. This would imply a type of imitation that would address each of our senses through mechanical devices so that no trace of context would disrupt the experience. Therefore, it differentiates an imitating space, the one that is not real, that we recognise as a diegetic space, from an imitated space, which is the lived space. The question of the model is thus raised, as it includes two reversed typologies: one corresponds to the simplified sample of a phenomenon. For example, those are our models of physical simulation. The other typology is a mathematical and computational construction, idealised to "understand what we observe in nature", as Henri Atlan states. Therefore, architecture completely immerses us into the diegetic space of our senses. The reproduction of this experience, for the sake of study or research, should not forget the immense synaesthesic capacities of our perceptions, which, thanks to compensation and substitution, are able to find and give meaning from the information of another, calling on memory. The representation operates on choices. If we want to imitate, we do not do so about a whole, but about prominent, characteristic elements that create meanings or sensations. The construction of an immersive space works in the same vein, so that the characterisation of the diegetic space happens through the mobilisation of references, the first being the ambiance. 